$>$ polysaccharide, I witnessed unexpected results. I was lost after days of measurements: how could the same polysaccharide give me different signals? When I approached my adviser, he suggested a technique I hadn't considered, and it helped me to uncover a difference in the composition of the polysaccharides that was behind the inconsistent signals.

Believe that more work is always better. We all get excited about where our latest data are taking us, and it's not uncommon to work a few night shifts or weekends to get all of the data you need. Once, a colleague and I were unable to determine whether our nanosensor was working correctly, even after we had desperately tried many instrumental methods. In despair, we temporarily abandoned the mission and took a break. Rest brought clarity: after our break, we had the energy we needed to find an alternative solution to our problem. When working on something non-stop for long periods of time, we can develop tunnel vision or burn out. Take a break and start afresh when necessary.

Your records should grow organically. Like most graduate students, I kept records in lab notebooks. This works for a few days, but not for an entire $\mathrm{PhD}$ project (especially when you are expected to handle multiple projects simultaneously). Keep clear records and maintain Excel sheets or Word documents with experimental logs. Build an appendix with links to the folders in which you've saved data, analysis and figures that you're about to publish. By the time I completed my PhD, I had 19 lab notebooks, and I would have been doomed without the help of Excel files, appendices and indexes. Find ways to protect and keep track of your data from the beginning don't wait for a haystack to form around your needle.

Get stuck after one failure. It's not easy to ditch a theory or an experiment you worked hard on. But knowing when to change direction is pivotal to success during a PhD. The first project I worked on as a graduate student was unsuccessful, despite 18 months of devotion. After this perceived failure, I was starting to feel disappointed. One day after a great discussion with my adviser, I moved on to a different project. After I worked out how to 'fail fast', I was able to dedicate my time to projects that brought me great success and eventually led to several interesting publications, research awards and fellowships.

Buddini Karawdeniya is a postdoctoral fellow at the Kim lab in the Lyle School of Engineering at Southern Methodist University, Dallas, Texas.

COLUMN

\title{
Biking through my PhD
}

\section{Overcoming my struggles after leaving China for my $\mathrm{PhD}$ has been like riding a bike, says Shuxuan Zheng.}

\section{BY SHUXUAN ZHENG}

$\mathrm{H}$ aving flown halfway around the world, I finally arrived in the Netherlands to start work on my $\mathrm{PhD}$ at the medical microbiology department of University Medical Center Utrecht.

I was delighted to think of all the things I would see and experience in this new and different world. That was until I saw the one thing that absolutely terrified me - a bicycle.

I had never learnt to ride a bike. Growing up in Qingdao, a hilly, seaside city in China without cycle paths, biking was dangerous. The local laws discourage it for safety reasons. Now, my Dutch neighbour was telling me I had to learn. She sold me a second-hand bike and pointed me to the car park. I upgraded my insurance and started practising.

It took me a week to learn, and a month to feel comfortable cycling. Now, after half a year, I am starting to enjoy it. For me, a helpful trick for dealing with Dutch traffic was to make a lot of noise as I rode: squawks, loud laughs, "look out", "watch it", and so on. This frightened other cyclists into keeping away from me, and prevented the crashes that had seemed inevitable when I started.

Now I've got used to it, cycling has become a symbol of my growth, freedom and successful adjustment to $\mathrm{PhD}$ life in the Netherlands. This pattern, of a time of struggle followed by fun, was repeated with other aspects of my life in Utrecht. There were more 'bikes' that I needed to learn how to ride. One of them was time management.

During my seven years of training in veterinary medicine in China, I got used to the 'Chinese' schedule. We came to work at 8 a.m. and left at around 10 p.m., often working at the weekend. There wasn't much time left for a social life or hobbies, so you made your job your hobby, and your co-workers provided your social life. But in Utrecht, people come to work at 9 a.m. and leave at 6 p.m. - and as for working at the weekend, forget it. How do they get all their work done?

I initially assumed that nobody was working very hard, because of their shorter hours. But after a few months, I realized I was the one not working hard: just because I stayed at work later did not mean I worked harder. In fact, the other PhD students were all completely focused on their work during that eight-hour working period and were super organized, whereas I was taking endless 'breaks'. In reality, I was Facebooking, Instagramming and messing around when I could have been focusing on my studies.

All this time, I'd been struggling with my inefficient and poorly planned working hours, so I finally resolved to 'learn to ride the bike' again and adjusted my routine. After a few months, I found that my revised plan of action was much more efficient: I am now more engaged and productive, and I get to have a life after work for the first time.

Something else happened when I started my $\mathrm{PhD}$ - and, like a downhill stretch on a bicycle, it was very "Now I've welcome. I had gone got used to it, to an international cyclinghas boarding school becomeasymol when I was six, f and I spent most of of my growth, my childhood in a freedom and successful adjustment." relaxed and casual environment that gave me the freedom to explore without fear. I enjoyed this time of 'wildness'. But later in life, it became a problem for me - because I was unprepared for the constraints, as I saw them, of formal interactions in the Chinese workplace.

All that changed on the day I met Robert Jan Lebbink and Emmanuel Wiertz, my PhD supervisors. In the Netherlands, respect is based on your work, not on unnecessarily formal 'civility'. I know that I can just wander into their offices and ask a casual question without worrying about causing offence. This shift has been transformational for me and has made me much more comfortable at work.

Even though most of the changes I have faced were forced on me as a result of my move, I am thankful that they happened. I'm looking forward to the next cycling challenge I encounter. -

Shuxuan Zheng is a PhD student in virology at the Department of Medical Microbiology at University Medical Center Utrecht, in the Netherlands. 